\title{
The Role of Dolomite Powder on the Properties of Self Compacting Concrete
}

\author{
[ S Ahmad, M.A.Babrus and Ayub Elahi ]
}

\begin{abstract}
The Dolomite Powder (DP), as a filler material has been used in the Self Compacting Concrete (SCC), which regulates the segregation of fresh concrete as well as rendering favorable impacts on the deformability of the SCC. The current study addresses the investigation of effects of locally available DP along with the proportions of locally available Fly Ash (FA), on the properties of SCC. The other aspect of this research work deals with the search of economical filler material to be used in concrete without compromising the strength of concrete and within the prescribed guidelines of European Federation of National Associations Representing producers and applicators of specialist building products for concrete (EFNARC).The specimens of concrete were cast using variousmix ratios of DP and FA. On the basis of the results obtained, it was indicated that with the use of DP along with the proportions of FA, the SCC fulfilled the criteria of EFNARC both in the fresh state and the hardened state for practical purposes.
\end{abstract}

Keywords - Dolomite Powder, Fly ash, Self-Compacting Concrete, Segregation

\section{Introduction}

Self-Compacting Concrete (SCC) can be defined as a fresh concrete which possesses superior flow-ability under maintained stability (i.e. no segregation) thus allowing selfcompaction i.e., material consolidation without addition of energy. [1]. SCC was first developed by Professor Okamura in 1988, with the intentions of improving the durability related properties of concrete structures [2]. At initial stages the SCC technology was based on the use of conventional super plasticizer (SP) for creation of highly fluid concrete. The use of viscosity-modifying agents (VMA) was induced forincreasing the plastic viscosity,hence aiding the prevention of segregation to a fluiditylevel which would normally cause segregation. SCC is a flowing type concrete mixture which is capable of consolidating under its own weight. The SCC, due to its exceptional fluid nature, makes it applicable for placing in tough, inaccessible conditions and in sections with congested reinforcement. With the development of polycarboxylate based SP and further improvements in aggregates optimization, the SCC quality

\section{S Ahmad}

HoD, Civil Engg, Comsats Institute of Information Technology, Wah Campus, Pakistan

\section{Ayub Elahi}

Professor, Civil Engg Department, UET Taxila Pakistan was enhanced at reduced material cost, often without the use of a VMA. [3]. VMAs have been in use for quite some time now [4].The primary use in the past was in underwater concreting, but nowadays they are being used in SCC. Wide range of studies have also been carriedout on the use of different forms of high range water reducing admixtures (HRWRA) with or without the use of VMAs in SCC [5-7]. Use of SCC also helpsto curtailnoise-related problems on the worksite whichare interlinked with the equipment used for vibration of concrete. Additional advantage of SCC is the reduction of time for placing the concrete in large sections [8].Therefore, SCC is a suitable choice for wider range of concrete structures especially in the complex shape of formwork and congested reinforcement. The mix proportions and composition of SCC differs from that of ordinary concrete. SCC usually requires a low water/binder (W/B) ratio i.e. in range of $0.30-0.40$, at the same time requires high cement content, and small amount of coarse aggregate [9]. Apart from the basic constituents of normal concrete, SCC requires several other ingredients such as supplementary cementitious materials (SCMs) and highrange water reducer. For achieving the self-consolidation capacity, the use of high-range water reducing admixtures is mandatory[10]. SCC also includessecondary cementitious materials called as fillers or powders, when the crushed size is less than $0.125 \mathrm{~mm}$, mainly to improve the strength and durability of concrete [11]. The role of secondary materials is to improve the packing and hence reducing the void contents of the whole mix. However, theseSCMs do have an influence on the workability of SCC especially in filling ability, passing ability and segregation resistance [12]. Depending on the type of SCMs, the effects can be positive or negative for the aforementioned SCC properties. A SCMwhich may be increasing the filling ability and passing ability simultaneously but is not certain to improve the segregation resistance of SCC [9]. The use of FA in concrete is increasing, growing prices of cement and pressure from environmental activists are boosting the use of secondary raw materials as a replacement of cement in concrete. [13]. The world production of FA is approximately over $600 \mathrm{M}$ tones[14]. FA has proved to be a practical and useful addition for SCC providing reduced sensitivity to changes in water content andenhanced cohesion, however, increased amounts of fly ash are likely to produce highly cohesive paste which may prove to be flow resistant. [15].FA replacing some of the cement will however increase the paste volume [16]. Also due to slow pozzolanic reaction, in presence of high volume FA, the compressive strength of concrete at higher ages will be generally good [16]. Theuse of alternative raw materials is cost-effective, provided that FA is a locally available low-cost byproduct.FAimparts a positive impactin reducingthe emissions and at the same time enhancing the consistency at low water-binder ratio (w/b) of SCC [17]. In addition to FA, mineral additives i.e. 
reactive or inert, have been introduced as partial cement replacement. Materials like met kaolin, ground granulated blast furnace slag, natural pozzolana and other fine fillers have been employed as additions to SCC, however,both short and long term effects of the these fillers on various characteristics of concrete still require betterevaluation. [18]. The use of mineral additivesin fresh and hardened stateof SCC was found to produce advantageousproperties. The reuse of agricultural and industrial byproducts in concrete production resultedin reduction of greenhouse gases into the atmosphere. Extensive studies have been carried out on the use of the more common mineral additives such as; fine limestone powder [19-22], pulverized-fuel ash [23-26], silica fume [27-30], hence their effects on SCC are somewhat expectable.

This paper primarily investigates the effects of use of Dolomite Powder (DP) and FA on both fresh and hardened state properties of SCC.The sources of said materials however have the local origins and are, thereby, potentially cost-effective. The principal objective of this research was to investigate and analyze the possibility of using locally available FA and DP in the production of SCC. The changes in both the fresh and the hardened properties of SCC accordingly with varying the mix proportions materials were examined and presented. The research was envisaged for obtaining the dual benefits in terms of low cost replacement material as well as best possible solution for the disposal and environmental hazardslinked with these materials by successful utilization of FA and DP in SCC mixes.

\section{Experimental Program}

\section{A. Materials and Mix Proportions}

\subsection{Materials}

Ordinary Portland cement conforming to BS EN 1971:2000 [31], was used. The fine aggregate used was graded between the $600 \mu \mathrm{m}$ and $150 \mu \mathrm{m}$ sieve. The coarse aggregate (Margalla crush) between the fractions of the 20 $\mathrm{mm}$ and $10 \mathrm{~mm}$ size were mixed in equal proportions by mass for use in the SCC mix. The physical properties of the coarseand fineaggregate are summarized in Table 1.

The dosage of SP i.e. (high-range water reducer) was varied accordingly with the variations of FA and DP, ensuring that the fresh state properties of all the mixes were almost the same.

Table: 1 Physical Properties of Fine \& Coarse Aggregates.

$$
\begin{array}{ccc}
\text { Physical } & \text { Dry } & \text { Bulk } \\
\text { Podded Unit } & \begin{array}{c}
\text { Busperties } \\
\text { mass } \\
(\mathrm{kg} / \mathrm{m} 3)
\end{array} & \text { Gravity (SSD) }
\end{array}
$$

Absorption $(\%)$

Fineness Modulus

\begin{tabular}{ccccc}
$\begin{array}{c}\text { Fine } \\
\text { Agregate }\end{array}$ & 1571 & 2.71 & 3.6 & 1.68 \\
$\begin{array}{c}\text { Coarse } \\
\text { ggregate }\end{array}$ & 1481 & 2.68 & 1.4 & - \\
\hline
\end{tabular}

The FA was obtained from the Olympia Chemicals plant site in the Warcha Salt range, Punjab, Pakistan and this was Class F, in accordance with theASTM C 618-03. DP used was obtained from a commercial rock crushing plant located at Khairabad, Punjab, Pakistan.However the quarries of dolomite stones were located in Swabi, KPK, Pakistan. The physical and chemical properties of both FA and DP, along with those of the Portland cement, are shown in Tables 2 and 3 respectively.

\subsection{Mix Proportions}

In the current study, five concrete mixes with altered proportions of FA and DP, each having the same/constant water binder ratioi.e 0.4 were tested. In order to maintain the self-compacting property on fresh state, the dosage of SP was adjusted for different mixes. The designations of the resulting specimens and mix proportions are presented in Tables 4 and 5 respectively.

Table: $2 \quad$ Physical Property of Powders.

\begin{tabular}{cccl}
\hline $\begin{array}{c}\text { Property } \\
\text { Evaluated }\end{array}$ & OPC & Fly Ash & $\begin{array}{l}\text { Dolomite } \\
\text { Powder }\end{array}$ \\
$\begin{array}{c}\text { Specific } \\
\text { Gravity }\end{array}$ & 3.03 & 2.5 & 2.58 \\
\hline
\end{tabular}

Table: 3

Chemical Properties of Powders.

\begin{tabular}{lllc}
\hline Chemical Composition & OPC & $\begin{array}{c}\text { Fly } \\
\text { Ash }\end{array}$ & $\begin{array}{l}\text { Dolomite } \\
\text { Powder }\end{array}$ \\
Silicon dioxide $\mathrm{SiO} 2$ & 21 & 39.76 & 4.94 \\
$\begin{array}{l}\text { Aluminum Oxide } \\
\text { Al2O3 }\end{array}$ & 5.04 & 2.27 & 1.96 \\
Ferric Oxide Fe2O3 & 3.24 & 32.73 & 0.61 \\
Calcium Oxide MgO & 61.7 & 8.01 & 40.05 \\
MagnesiumOxide MgO & 2.56 & 1.2 & 7.86 \\
Sulfur Oxide SO3 & 1.51 & 5.9 & 0.04 \\
Sodium Oxide Na2O & 0.06 & 0.47 & 0.03 \\
Potassium Oxide K2O & 0.52 & 0.83 & 0.45 \\
\hline
\end{tabular}

Table: 4

Designation of Specimens.

$\begin{array}{cc}\begin{array}{c}\text { Mix } \\ \text { Designation } \\ \text { Mix 1 }\end{array} & \begin{array}{c}\text { Proportions of Fine Aggregate and } \\ \text { Dolomite Powder }\end{array} \\ \text { Mix 2 } & 100 \% \text { FA } \\ \text { Mix 3 } & 50 \% \mathrm{FA}+25 \% \mathrm{FP}+50 \% \mathrm{DP} \\ \text { Mix 4 } & 25 \% \mathrm{FA}+75 \% \mathrm{DP} \\ \text { Mix 5 } & 100 \% \mathrm{DP} \\ \end{array}$

Table: 5 Mix Proportions. 


\begin{tabular}{cccccccc}
\hline Mix & W/B & $\begin{array}{c}\text { Cement Fly Ash Dolomite } \\
\mathrm{Kg} / \mathrm{m}^{3}\end{array}$ & $\begin{array}{c}\text { Aggregate } \\
\mathrm{Kg} / \mathrm{m}^{3}\end{array}$ & $\begin{array}{c}\text { Powder } \\
\mathrm{Kg} / \mathrm{m}^{3}\end{array}$ & Fine & Coarse & $\begin{array}{c}\text { Super } \\
\text { Plasticizer } \\
(\% \text { by } \\
\text { mass of }\end{array}$ \\
Mix 1 & 0.4 & 290 & 290 & - & 975 & 650 & 2 \\
Mix 2 & 0.4 & 290 & 217.5 & 72.5 & 975 & 650 & 1.5 \\
Mix 3 & 0.4 & 290 & 145 & 145 & 975 & 650 & 2.5 \\
Mix 4 & 0.4 & 290 & 72.5 & 217.5 & 975 & 650 & 1.78 \\
Mix 5 & 0.4 & 290 & - & 290 & 975 & 650 & 2 \\
\hline
\end{tabular}

\section{B. Experimental Program and Test Procedure.}

2.1 Variables

The variables applied in the current study are:

Proportions of FA and DP (1:0, 3:1, 1:1, 1:3,0:1).

Quantity of polycarboxylate based SP.

The subsequentfactors were taken as constantin the study:

Gross amount of powder/ binder content (Cement + FA + $\mathrm{DP})=580 \mathrm{~kg} / \mathrm{m} 3$.

Total amount of cement content $=290 \mathrm{~kg} / \mathrm{m} 3$.

Water-binder ratio $=0.40$.

Type of admixture: Polycarboxylate based SP.

The ratio of fine aggregate to coarse aggregate content $=$ 3:2 (by mass).

Margalla crushwas used as coarse aggregate in combinations of a $20 \mathrm{~mm}$ and $10 \mathrm{~mm}$ sizes in (1:1) mass proportion.

\subsection{Preparation and curing of test specimens}

From each concrete mix, six 100 x $200 \mathrm{~mm}$ cylinders were cast. The cylinders were used to calculate the compressive strength at hardened state. The specimens were kept in the casting room at $25( \pm 1){ }^{\circ} \mathrm{C}$ for $24 \mathrm{~h}$ and were covered with plastic sheets. The samples were then demolded and shifted to the curing room at $25( \pm 1){ }^{\circ} \mathrm{C}$, jute bags were used for covering the samples to keep the moisture constant. The samples were kept under the same condition until taken out for the testing.

\subsection{Testing of specimens}

The freshly mixed SCC samples were tested for filling ability, passing ability, viscosity and segregationresistance. Slump flow and T500 mm spread time, V-funnel test, L-box test and Sieve segregation resistance test were conducted as per guidelines of the EFNARC evaluating the filling ability, passing ability and segregation resistance of SCC respectively. A concise introduction of the said tests is given in the following passages.

\subsubsection{Slump-flow and T500 time}

The slump-flow and T500time is a test for evaluating the flow-ability and the flow rate of SCC in the absence of external obstructions. The test is based on the descriptions in EN 12350-2:2000 [33]. The resultsare indicative of the filling ability of SCC. The T500 time is a suggestive of the speed of flow and hence the viscosity of the SCC. The following table defines the slump flow classes.

Table: $6 \quad$ Slump Flow Classes.

\begin{tabular}{lr}
\hline Class & $\begin{array}{l}\text { Slump flow in } \\
\text { mm }\end{array}$ \\
SF1 & 550 to 650 \\
SF2 & 660 to 750 \\
SF3 & 760 to 850 \\
\hline
\end{tabular}

The slump cone was filled in with a concrete sample as used for the BS EN 12350-2:2000 [33] slump test. As the cone was lifted upwards, the time from beginning of upward movement of the cone to when the concrete had flowed to a diameter of $500 \mathrm{~mm}$ was measured; this time was recorded as the T500 time. The slump flow measurement was calculated as the mean of largest diameter of the flow spread of the concrete and the diameter of the spread at right angles to it.

\subsubsection{V-funnel test}

The V-funnel test is employed to check the viscosity and filling-ability of SCC. The following table defines the Viscosity classes.

Table: $7 \quad$ Viscosity Classes.

\begin{tabular}{lrc}
\hline Class & T500, s $\begin{array}{c}\text { V-funnel } \\
\text { time in } \mathrm{s}\end{array}$ \\
$\mathrm{VS} 1 / \mathrm{VF} 1$ & $\leq 2$ & $\leq 8$ \\
$\mathrm{VS} 2 / \mathrm{VF} 2$ & $>2$ & 9 to 25 \\
\hline
\end{tabular}

A V shaped funnel was filled with fresh concrete, a sample of $12 \mathrm{~L}$ was obtained in accordance with BS EN 12350-1:2000 [32], and the time taken by the concrete in flowing out of the funnel was noted and recorded as the Vfunnel flow time. 


\subsubsection{L-box test}

The L-box test is devised toevaluate the passing ability of SCC to flow through tight openings and congested spaces between reinforcing bars along with other obstructions without any hindrance or segregation. There are two variations of evaluation method; first is the two bar test and the second is three bar test. The three bar test imitates more congested reinforcement. The following table defines the passing ability classes.

Table: 8

Passing Ability Classes.

$\begin{array}{ll}\text { Class } & \text { Passing ability } \\ \text { PA1 } & \geq 0.80 \text { with } 2 \text { rebars } \\ \text { PA2 } & \geq 0.80 \text { with } 3 \text { rebars }\end{array}$

A calculated volume of fresh concrete was set to flow in horizontal plane through the vertical gaps between the smooth reinforcing bars. The height of the concrete volume beyond the reinforcement was measured.

\subsubsection{Sieve segregation resistance test}

The sieve segregation resistance test is used to determine the ability of SCC against segregation. Following table defines the segregation resistance classes.

Table: 9 Segregation Resistance Classes.

\begin{tabular}{lc}
\hline Class & Segregation resistance in $\%$ \\
SR1 & $\leq 20$ \\
& \\
SR2 & $\leq 15$
\end{tabular}

For segregation resistance, the sample of fresh concrete was taken and was left to stand for 15 min during which any emerging bleed water was noted. The sample was then carefully poured into a cleaned sieve,having $5 \mathrm{~mm}$ square apertures. After interval of 2 minutes, the weight of material passing through the sieve was noted. The segregation ratio was then determined as the proportion of the concrete sample which passed through the sieve.

\section{Results and discussions}

The results of the test conducted in the fresh state of concrete are summarized in Table 10 below;

Table 10: Classification of mixes in Fresh State.

\begin{tabular}{llllll}
\hline Standard & Mix 1 & Mix 2 & Mix 3 & Mix 4 & Mix 5 \\
Test & & & & & \\
Slump Flow & SF 1 & SF 1 & SF 1 & SF 1 & SF 1 \\
T $_{500}$ time & VS 2 & VS 2 & VS 2 & VS 2 & VS 2 \\
V-funnel & VF 2 & VF 1 & VF 1 & VF 2 & VF1 \\
L-box & n.a & n.a & n.a & PA 2 & PA 2 \\
$\begin{array}{l}\text { Sieve } \\
\text { segregation } \\
\text { resistance }\end{array}$ & SR 1 & SR 1 & SR 1 & SR 1 & SR 1 \\
\hline
\end{tabular}

\section{Discussion}

1. Since the dosage of the SP was also variable apart from the proportions of the filler materials. The dosage of the SP was adjusted so to keep the fresh concrete in a relatively flowing consistency and at the same time keeping the W/B at constant. The graph for the dosage of the SP shows a relatively stable trend with maximum and minimum values ranging from 2.5 - 1.5. The maximum value is noted at the mix 3 whereas the minimum at mix 2 . The overall behavior is fluctuating considering the variation in the proportions of the fillers in the mixes.

\section{The graph is shown as:}

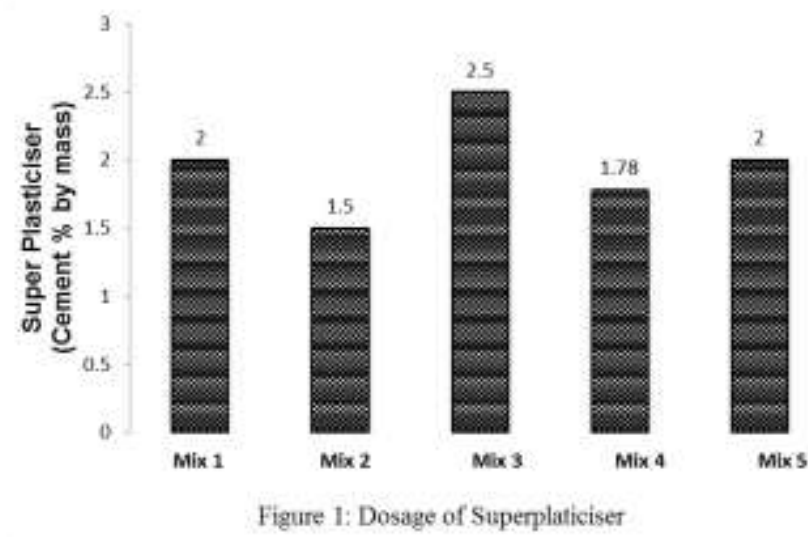

3. As per EFNARC guidelines for testing of concrete in fresh state for slump measurement, all the mixes fall into the SF1 category with range of 550 to $650 \mathrm{~mm}$ flow. 


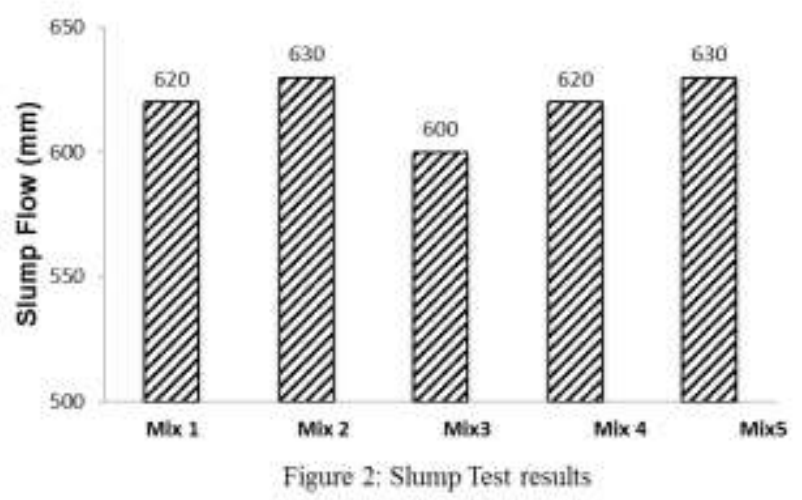

The above graph represents the trend of Slump Flow test with the changes of the mix proportions of the filler materials in the SCC. The initial mixes show an increasing trend in the slump flow with the decreasing proportions of FA i.e from $100 \%$ to $75 \%$. However the mix 3 shows a significant loss of slump with an equal proportions of FA and DP in the mix i.e having the $50 \%$ contents each. The latter two mixes show an identical trend as the first two. However, the later mixes have higher contents of DP e.g. $100 \%$.

As per the EFNARC guidelines for Slump flow at $T_{500}$ $\mathrm{mm}$ all the mixes fall into the category of VS2 with time range of $>2$ seconds.

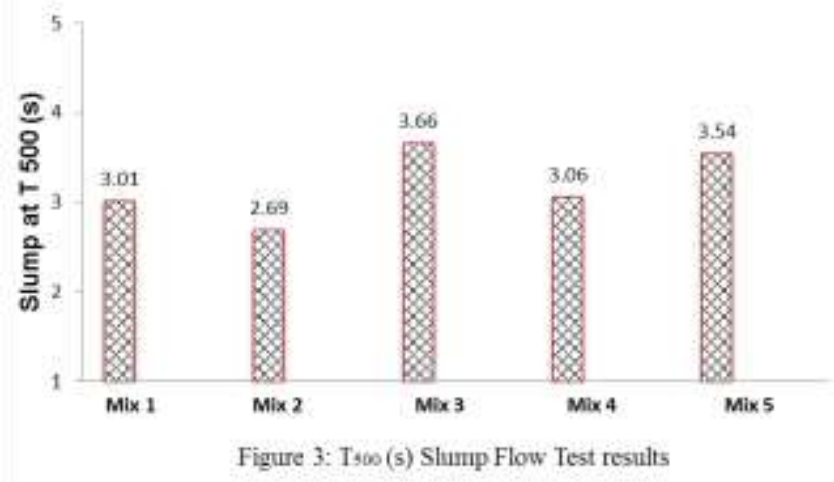

The graph for the $T_{500}$ slump flow shows quite fluctuations with a starting time of 3.01 seconds for the mix 1. However no regular trend is being followed as the proportions of FA is being reduced from mix 1 to mix 5 . The peak time taken to attain the desired slump is noted in the mix 3 which has the equal proportions of FA and DP both at $50 \%$. However the general trend is increase in time with the increasing contents of DP starting from mix 2.

1. As per the EFNARC guidelines for $V$-funnel flow time, Mix 2, Mix 3\& Mix 5 fall into VF1 category with time range of $\leq 8 \mathrm{sec}$, while Mix 1 , Mix 4 fall into category of VF2 with time range of 9 to 25 seconds.+

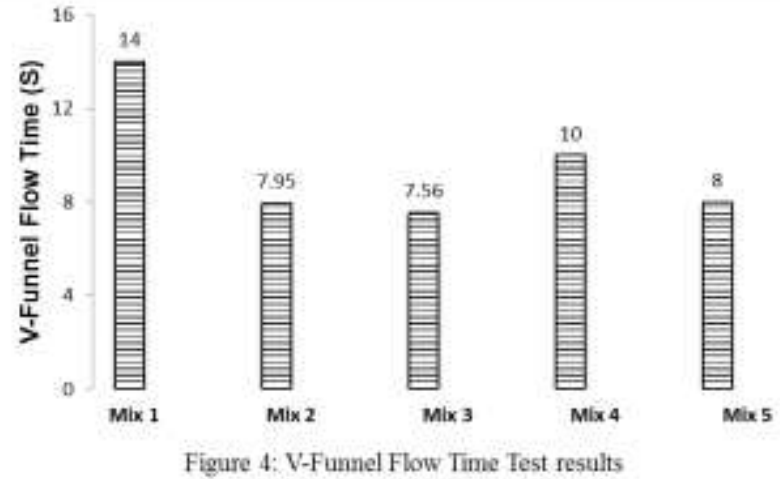

The above presented graphical results for the $V$ Funnel flow time portray a sharp reduction of time starting from the mix 1 with $100 \%$ FA contents. The initial decline in time is significant which achieves a stable value for the mix 2 and 3 with the introduction of DP with percentage contents of 25 and $50 \%$ respectively. Again for the mix 4 a jump is observed in the time scale which is soon followed by a drop for the final mix. To sum up the results, the general trend is nearly stable after the first mix with the peak value of 14 seconds.

2. As per the EFNARC guidelines for L-box test, Mix 1, Mix 2 \& Mix 3 fall under the minimum requirement of $\geq 0.8$ with 3 rebar, while Mix 4 \& Mix 5 fall into category ofPA2 with range of $\geq 0.8$ with 3 rebar.

The L-Box ratio test shows a steady declining trend for the first 3 mixes reaching the minimum value at the mix 3. The last two mixes which have a higher content of DP show higher values so to achieve the classification of PA2. The first three mixes have the values well below the minimum designated values of the test.

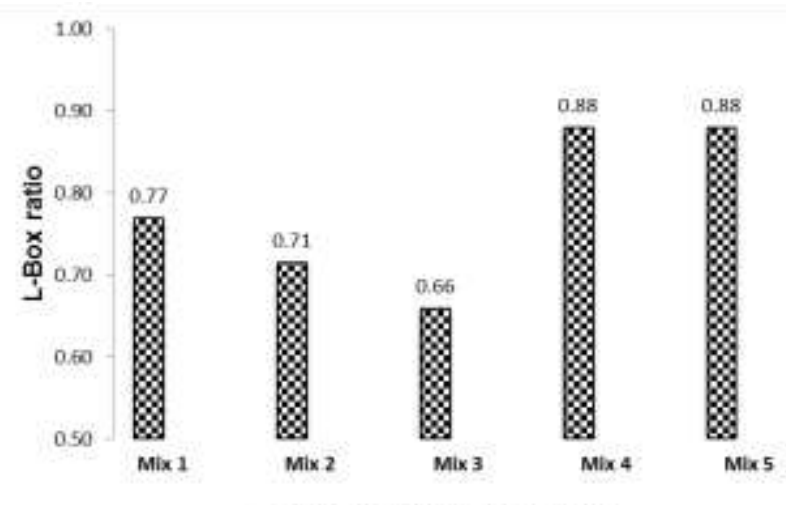

Figure 5: L-Box ratio Test results

3. As per the EFNARC guidelines for segregation resistance (sieve resistance) all the mixes fall into SR1 category with range $\leq 20(\%)$ when the results are rounded to the nearest $1 \%$. 


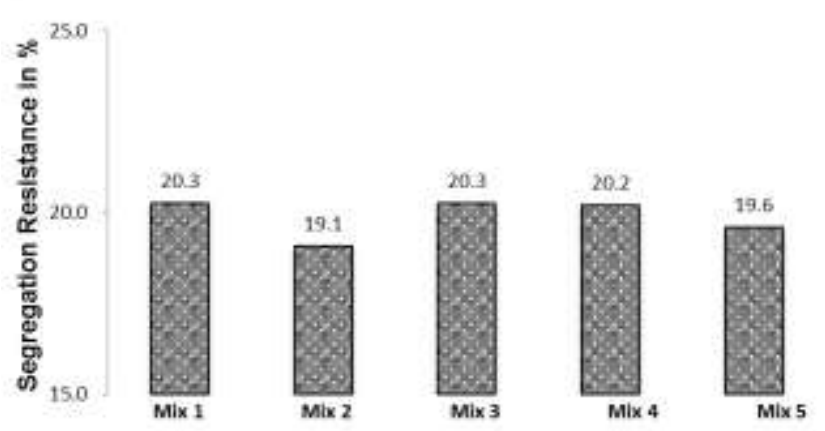

Figure 6: Sieve Segragation Resistance Test

Out of all the test results, the graph of the Sieve Segregation test represents a very stable trend. The overall effect on the segregation potential of concrete is almost identical in every mix even with the changing proportions of the filler materials. The lowest values for the percentage segregation is noted in the mix 2 followed by mix 5 . The other three mixes have nearly identical values.

4. The graphical results of the compressive strength of the mixes represent an irregular behavior in terms of strength achieved by the mixes with decreasing percentage of FA contents or conversely increasing trend of DP contents. The 3 days strength values show a gradual increasing trend in the strength achievement with the increasing amounts of DP. However this is not the case for the 7 days values which show an increasing trend for the mixes 1 to 3 reaching the maximum strength for the mix having the equal proportions of the FA and DP in the mix, followed by a gradual decline in strength. The 28 days values present a much more erratic behavior as compared to 3 and 7 days values. The maximum strength is achieved with the mix 3, immediately followed by a minimum value at mix 4 . No general trend can be concluded based on the results, however, the overall strength achieved by the mixes is very satisfactory.

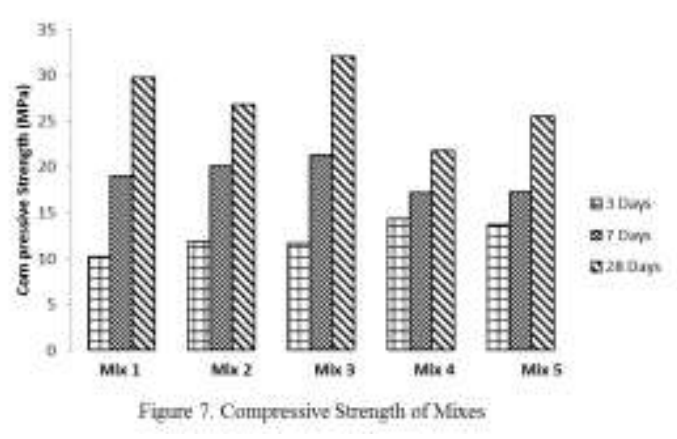

\section{Conclusions}

The results for all the trial mixes were well within the prescribed limits and were very satisfactory both in fresh state and hardened state. Based on the results of the test following conclusion have be drawn;

The minimum quantity of SP was used in the Mix 2, wherein the proportion of FA and DP was 3:1.

It is possible to manufacture SCC using locally available FA and DP with acceptable fresh and hardened properties.

As per EFNARC guide for making SCC, all the mixes with DP and FA are categorize as SF1 in slump flow category.

In terms of viscosity the mixes are classified as VS2 on basis of T500 test and the Mix 2, Mix 3\& Mix 5 as VF1, while Mix $1 \&$ Mix 4 fall into category of VF2 based on Vfunnel flow time.

\section{References}

[1] Goodier, C.I. (2003). "Development of SCC.” Proceedings of the Institution of Civil Engineers Structures \& Buildings, Issue SB4, 156, pp.405-414.

[2] Okamura, H., Ouchi, M., (2003). "Applications of SCC in Japan.” Proceedings of the 3rd International RILEM Symposium on SCC, O. Wallevik and I. Nielsson, Ed., RILEM Publications, pp. 3-5.

[3] Grace, W.R. (2005) "An Introduction to Self-Consolidating Concrete (SCC)". Technical Bulletin TB-1500. <http://www.na.graceconstruction.com/custom/concrete/ downloads/tb_1500b.pdf.> (Oct. 7, 2013).

[4] Khayat, K.H. (1998). "Viscosity Enhancing Admixtures for Cement - based materials: An Overview." Cement and Concrete Composites, Vol. 20, No. 2-3, pp. 171-188.

[5] Khayat, K.H., Yahia, A. (1997). "Effect of Welan Gum - High Range Water Reducer Combinations on Rheology of Cement Grout." ACI Materials Journal, Vol.94, No. 5, pp. 365-372.

[6] Sari, M., Prat, E., Labastire, J.F. (1999). "High Strength Self Compacting Concrete: Original Solutions Associating Organic and Inorganic Admixtures." Cement and Concrete Research, Vol. 29, No. 6, pp. 813-818.

[7] Lachemi, M., Hossain, K.M.A., Lambros, V., Nkinamubanzi, P.C., Bouzoubaa, N. (2004). "Performance of New Viscosity Modifying Admixtures in Enhancing the Rheological Properties of Cement Paste." Cement and Concrete Research, Vol. 34, No. 2, pp. 185-193.

[8] Santhnam, M. (2011). "Self-Compacting Concrete." <http://www.theconcreteportal.com/scc.html> (Oct. 5, 2013).

[9] Safi uddin Md. (2008). "Development of Self-Consolidating High Performance Concrete Incorporating Rice Husk Ash." Ph.D. Thesis, The University of Waterloo, Waterloo, Ontario, Canada.

[10] Safi uddin Md., West J.S.,Soudki K.A. (2010). "Flowing Ability of Self-Consolidating Concrete and Its Paste and Mortar Components Incorporating Rice Husk Ash." Canadian Journal of Civil Engineering, No. 37, pp. 401-412.

[11] Safi uddin Md., West J.S., Soudki K.A. (2010)."Hardened Properties of Self-Consolidating High Performance Concrete Including Rice Husk Ash." Cement and Concrete Composites, No. 32, pp. 708-717.

[12] Safi uddin Md., West J.S.,Soudki K.A. (2011). "Flowing Ability of the Mortars Formulated from Self-Compacting Concretes Incorporating Rice Husk Ash." Construction and Building Materials, No. 25, pp. 973-978.

[13] Rizwan, S.A., Bier, T.A., Ahmad, H. (2007). "SCC - A Useful Technology." Pakistan Engineering Congress, 70th Annual Session Proceedings, Paper No.670, pp. 293-319.

[14] Joshi, R.C., Lohita, R.P., (1997). "Fly Ash in Concrete: Production, Properties and Uses". Issue 2 of Advances in Concrete Technology. CRC Press.

[15] Bremseth, S.K. (2010). "FA in Concrete - A Literature Study of the Advantages and Disadvantages." COIN Project Report No 18. <http://www.coinweb.no/files/Reports/Fly\%20ash\%20in\%20concrete \%20-\%20literature\%20study.> (Dec. 3, 2013). 
[16] Bilodeau, A., Malhotra, V.M., Seabrook, P.T. (2001). "Materials Technology Laboratory: Use of High Volume Fly Ash Concrete at the Liu Center - Case Study report." CANMET Energy Technology Center, Natural Resources Canada.

[17] Vikan H., Hammer T.A., Kjellsen K.O. (2010). "Drying Shrinkage of SCC - Influence of Ternary Composite Cements in Design, Production and Placement of Self-Consolidating Concrete.' Proceedings of SCC RILEM Conference, Montreal, Canada, K.H. Khayat and D. FeysEd. Springer,New York,2010, pp. 271-281.

[18] European Federation of National Associations Representing producers and applicators of specialist building products for Concrete (EFNARC). "The European Guidelines for SCC - Specification, Production and Use. (2005)." <http://www.efnarc.org/pdf/> (Oct. 3, 2013).

[19] Ye, G., Liu, X., De Schutter, G.,Poppe, A.M.,Taerwe, L. (2007). "Influence of limestone powder used as filler in SCC on hydration and microstructure of cement pastes."Cement and Concrete Composites, No. 29, pp. 94-102.

[20] Felekoglu, B. (2007). "Utilization of high volumes of limestone quarry wastes in concrete industry (self-compacting concrete case)."Resources,Conservation and Recycling, No.51, pp. 770-791.

[21] Esping, O. (2008). "Effect of limestone filler BET(H O)-area on the fresh and hardened properties of self-compacting concrete."Cement and Concrete Research,No. 38, pp. 938-944.

[22] Topcu, I.B.,Uygunoglu, T. (2010). "Influence of mineral additive type on slump-flow and yield stress of self-consolidating mortar."Scientific Research and Essays, Vol5, No. 12, pp. 1492-1500.

[23] Sukumar, B.(2008). "Evaluation of strength at early ages of selfcompacting concrete with high volume fly ash."Construction and Building Materials,No. 22, pp. 1394-1401.

[24] Sahmaran, M. (2009). "Transport and mechanical properties of selfconsolidating concrete with high volume fly ash."Cement and Concrete Composites, No.31, pp. 99-106.

[25] Liu, M. (2010). "Self-compacting concrete with different levels of pulverized fuel ash."Construction and Building Materials, No. 24, pp. $1245-1252$

[26] Siddique, R. (2011). "Properties of self-compacting concrete containing class F fly ash."Materials and Design, No. 32, pp. 15021507.

[27] Yazici, H. (2008). "The effect of silica fume and high-volume Class $\mathrm{C}$ fly ash on mechanical properties, chloride penetration and freezethaw resistance of self-compacting concrete."Construction and Building Materials, No.22, pp. 456-462.

[28] Turkel, S.,Altuntas, Y. (2009). "The effect of limestone powder, fly ash and silica fume on the properties of self-compacting repair mortars."Sadhana (India), Vol. 34, No. 2, pp. 331-343.

[29] Gesoglu, M.,Guneyisi, E.,Ozbay, E. (2009). "Properties of selfcompacting concretes made with binary,ternary, and quaternary cementitious blends of fly ash, blast furnace slag, and silica fume."Construction and Building Materials,No. 23, pp. 1847-1854.

[30] Guneyisi, E.,Gesoglu, M., and Ozbay, E. (2010). "Strength and drying shrinkageproperties of self-compacting concretes incorporating multisystem blendedmineral admixtures."Construction and Building Materials, No. 24, pp. 1878-1887.

[31] British Standard European Norm. BS EN 197-1:2000. "Cement Composition, specifications and conformity criteria for common cements." London, BSI

[32] British Standard European Norm. BS EN 12350-1:2000. "Testing Fresh Concrete. Sampling." London, BSI.

[33] British Standard European Norm. BS EN 12350-2:2000. "Testing Fresh Concrete. Slump Test.” London, BSI.

[34] G. Eason, B. Noble, and I. N. Sneddon, "On certain integrals of Lipschitz-Hankel type involving products of Bessel functions," Phil. Trans. Roy. Soc. London, vol. A247, pp. 529-551, April 1955. (references)

[35] J. Clerk Maxwell, A Treatise on Electricity and Magnetism, 3rd ed., vol. 2. Oxford: Clarendon, 1892, pp.68-73.

[36] I. S. Jacobs and C. P. Bean, "Fine particles, thin films and exchange anisotropy," in Magnetism, vol. III, G. T. Rado and H. Suhl, Eds. New York: Academic, 1963, pp. 271-350.

[37] K. Elissa, "Title of paper if known," unpublished.
[38] R. Nicole, "Title of paper with only first word capitalized," J. Name Stand. Abbrev., in press.

[39] Y. Yorozu, M. Hirano, K. Oka, and Y. Tagawa, "Electron spectroscopy studies on magneto-optical media and plastic substrate interface," IEEE Transl. J. Magn. Japan, vol. 2, pp. 740-741, August 1987 [Digests 9th Annual Conf. Magnetics Japan, p. 301, 1982].

[40] M. Young, The Technical Writer's Handbook. Mill Valley, CA: University Science, 1989 